\title{
\begin{tabular}{|c|c|} 
JURNAL EKONOMI DAN MANAJEMEN \\
P-ISSN: 2598-9022/ E-ISSN: 2598-9618 \\
Available at: http://e-journal.unipma.ac.id/index.php/capital
\end{tabular}
}

\section{Factors Predicting of Purchasing Decision Moslem Fashion Products in the New Normal Pandemic Covid-19 (Case Study in Madiun Municipality)}

\author{
Tatik Mulyati1), Arnedia Binada Duanti Putri ${ }^{2)}$ \\ ${ }^{1.2)}$ FakultasEkonomi, Universitas Merdeka Madiun \\ email: tatikmulyati@unmer-madiun.ac.id
}

\begin{abstract}
The economy and activities in various sectors and regions experienced a decline as a result of the Covid19 pandemic. With a variety of limitations, the new normal period is a necessity and is an opportunity to carry out economic recovery and strengthening, including fashion products. This study aims to determine the factors that influence purchasing decisions for moslem fashion products on Instagram. The sample used as many as 250 people with sampling techniques using non-probability sampling methods. The data collection method uses a questionnaire. Analysis of the data used is Multiple Linear Regression Analysis. The results showed that there were 3 factors that influenced purchasing decisions on moslem fashion products on Instagram, namely electronic word of mouth (eWOM), information quality and celebrity endorsement. These three factors partially or simultaneously have a significant influence on purchasing decisions for fashion products on Instagram.
\end{abstract}

Keywords: purchasing decisions, electronic word of mouth, information quality, celebrity endorsement

\section{Abstraksi}

Perekonomian dan aktivitas di berbagai sektor dan wilayah mengalami penurunan sebagai dampak adanya pandemi Covid-19. Dengan berbagai keterbatasan, masa new normal menjadi satu keharusan dan merupakan kesempatan untuk melakukan pemulihan serta penguatan ekonomi termasuk di dalamnya produk fashion. Penelitian ini bertujuan untuk mengetahui faktor-faktor yang memengaruhi keputusan pembelian produk fashion muslim. Sampel yang digunakan sebanyak 250 orang dengan teknik pengambilan sampel menggunakan metode non probability sampling. Metode pengumpulan data menggunakan kuesioner. Analisis data yang digunakan adalah Analisis Regresi Linear Berganda. Hasil penelitian menunjukkan bahwa ada 3 faktor yang memengaruhi keputusan pembelian produk fashion muslim yakni electronic word of mouth (eWOM), kualitas informasi dan celebrity endorsement. Ketiga faktor tersebut secara parsial maupun simultan memiliki pengaruh signifikan terhadap keputusan pembelian produk fashion muslim di Kota Madiun.

Kata kunci :keputusan pembelian, electronic word of mouth, kualitas informasi, celebrity endorsement

\section{A. Pendahuluan}

Pandemi Covid-19 telah memukul perekonomian secara global termasuk Indonesia. Dampaknya makin terasa dalam perekonomian dalam negeri, terutama dari sisi konsumsi, korporasi, sector keuangan, dan produksi karena tidak bisa menjalankan 
usaha secara normal.Perekonomian dan aktivitas di berbagai sektor dan wilayah mengalami penurunan akibat pandemi Covid-19. Seiring konstannya pasar keuangan domestik dan pulihnya beberapa sector perekonomian, economic shock berangsur mereda. Terdapat risiko tinggi untuk menggerakkan kembali berbagai roda aktivitas sosial dan ekonomi secara normal. Dengan berbagai keterbatasan, masa new normal menjadi satu keharusan, dan merupakan kesempatan untuk melakukan pemulihan serta penguatan ekonomi (Modjo, 2020).

Meskipun terdampak Covid-19, saat ini kebutuhan dan permintaan masyarakat terhadap kebutuhan primer, sekunder maupun tersier semakin beragam. Hal ini merupakan peluang bagi perusahaan untuk menawarkan berbagai pilihan produk dengan beragam kualitas. Hal ini membuat calon konsumen merasa kebingungan memilih produk, sehingga sebelum melakukan pembelian harus mengumpulkan informasi dan menyeleksi produk yang akandibeli agar sesuai kebutuhan.

Dalam dinamika pemasaran, konsumen selalu mencari referensi dan lebih memercayai opini komunitas tentang suatu produk, sering disebut dengan word of mouth (WOM), yang berperan besar dalam pengambilan keputusan pembelian dan pembentukan pola perilaku konsumen. Pesatnya kemajuan teknologi khususnya jaringan internet mampu memberikan berbagai pilihan informasi mengenai suatu produk sehingga memungkinkan adanya sebuah komunikasi word of mouth yang tidak hanya menjadi sebuah bentuk komunikasi person to person mengenai sebuah produk, layanan ataupun merek tapi mampu menjadi bermacam bentuk komunikasiWOM yang merambah secara mendunia melalui media online dan sering disebut electronic word of mouth atau eWOM(Wijaya \& Paramita, 2014).

Kualitas informasi yang disampaikan di media sosial instagram tentang suatu produk akan memengaruhi opini konsumen. Informasi tersebut berguna dan relevan dalam memprediksi kualitas dan kegunaan produk atau jasa sehingga harusup to date untuk memuaskan kebutuhan konsumen atau pembeli online. Hal tersebut dapat membantu pembeli dalam membuat keputusan, konsisten dan mudah dipahami. Kualitas informasi mengenai suatu produk sangat penting, karena dapat memberikan alas an kuat bagi calon konsumen untuk tertarik atau tidak menggunakan produk tersebut. Konsumen tertarik dengan produk yang ditawarkan melalui instagram karena informasi yang diberikan cukup menarik(Rizki et al., 2015).

67|CA PIT A L, V OL UME 4, NOMOR 1, SEPTEMBER 2020 
Pihak lain yang ikut menawarkan atau menggunakan jasa orang lain untuk memengaruhi konsumen khususnya pengguna instagram adalah celebrity endorsement, yang merupakan salah satu strategi perusahaan agar produk bisa lebih dikenal; biasanya dilakukan oleh selebritis favorit, sehingga produk apapun yang digunakan akan sangat diinginkan oleh penggemarnya. Hal ini menjadi peluang karena produk yang direkomendasikan lebih mudah diterima masyarakat. Celebrity endorsement merupakan alat promosi yang popular karena menggunakan selebriti sehingga dapat menarik, menyenangkan dan dapat dipercaya oleh public sehingga produk yang dipromosikan dapat diketahui dan dikenal oleh konsumen dan merupakan bagian terpenting dari sebuah strategi promosi kampanye pemasaran suatu produk (Superwiratni, 2018).

Keputusan pembelian merupakan proses konsumen memperoleh informasi mengenai suatu produk dan menentukan pilihan yang terbaik dari beberapa pilihan yang ada. Produk fashion muslim dipilih karena produk tersebut memiliki perkembangan yang membutuhkan informasi lebih lanjut mengenai model terbaru. Konsumen dapat dengan mudah mencari informasi mengenai fashion muslim melalui internet, sehingga tertarik untuk membeli model terbaru.

Tabel 1. Top Brand Index

\begin{tabular}{|l|c|c|l|c|c|}
\hline \multicolumn{3}{|c|}{ KategoriBusana Muslim } & \multicolumn{3}{c|}{ Kategori Baju Koko } \\
\hline BRAND & TBI & Category & BRAND & TBI 2020 & Category \\
\hline Rabbani & $19.6 \%$ & TOP & Rabbani & $22.2 \%$ & TOP \\
\hline Almadani & $17.4 \%$ & TOP & Al Mia & $16.2 \%$ & TOP \\
\hline Zoya & $13.6 \%$ & TOP & Atlas & $14.8 \%$ & TOP \\
\hline Azka & $9.5 \%$ & & Dannis & $13.6 \%$ & \\
\hline Attena & $8.9 \%$ & & Zoya & $2.0 \%$ & \\
\hline
\end{tabular}

Sumber: Top Brand Award (2020)

Berdasarkan tabel tersebut, terdapat lima produk fashion muslim yang dikenal oleh masyarakat Indonesia. Produk Rabbani menempati posisi teratas dalam kategori busana muslim pria dan wanita.

\section{B. TINJAUAN PUSTAKA}

\section{Keputusan Pembelian}

(Shandy, 2018) menyatakan bahwa keputusan pembelian adalah keputusan yang diambil seseorang tentang produk mana yang akan dibeli dengan memilih satu dari beberapa alternatif pilihan yang ada. Keputusan selalu mensyaratkan pilihan diantara perilaku yang berbeda.

68 | C A P I T A L, V O L UME 4, NOMOR 1, SEPTEMBER 2020 
(Rizki et al., 2015) menjelaskan bahwa setiap keputusan pembelian mempunyai struktur sebanyak tujuh komponen, yaitu keputusan tentang: jenis produk, bentuk produk merek, penjualan, jumlah produk, waktu pembelian dan waktu pembelian.

\section{Electronic Word of Mouth (eWoM)}

(Restanti et al., 2019)menjelaskan bahwa Electronic Word of Mouth (eWoM) adalah sebuah pernyataan positif maupun negatif yang dilakukan oleh pelanggan potensial ataupun mantan pelanggan mengenai suatu produk atau perusahaan, yang ditujukan untuk banyak orang atau lembaga melalui media internet. Terdapat delapan dimensi yang berfokus pada eWoM yaitu: Platform Assistance; Concern for Others Consumers; Economic Intensives; Helping the Company; Expressing Positive Feelings; Venting Negative Feelings; Social Benefits dan Advice Seeking.

(Rachmalika, 2015) menyatakan proses pemasaran dengan menggunakan eWoM dinilai lebih efektif bila diterapkan pada akun media sosial yang kini dapat dijamah oleh masyarakat luas. Terlebih lagi $e W o M$ dapat menyediakan sarana yang luas untuk dapat memengaruhi keputusan seseorang dalam membeli sebuah merk, jasa, ataupun produk tertentu.

\section{Kualitas Informasi}

(Nazarudin \& Pela, 2016) mendefinisikan kualitas informasi adalah seberapa besar suatu informasi tentang produk dan jasa berguna dan relevan bagi pembeli online dalam memprediksi kualitas dan utilitas suatu produk dan jasa yang ditawarkan pada online shop.

(Gunawan \& Ayuningtiyas, 2018) menyatakan bahwa di dalam online shopping sebaiknya menyajikan informasi yang mencakup produk dan jasa yang ada. Informasi tersebut berguna dan relevan dalam memprediksi kualitas dan kegunaan produk atau jasa dan harus up-to-date untuk memuaskan kebutuhan konsumen atau pembeli online. Hal tersebut dapat membantu pembeli dalam membuat keputusan, konsisten dan mudah dipahami. Kualitas informasi tergantung pada tiga hal, yaitu informasi harus akurat, tepat waktu, dan relevan.

69|CA P I T A L, V O L UME 4, NOMOR 1, SEPTEMBER 2020 


\section{Celebrity Endorser}

Penelitian yang dilakukan (Knoll \& Matthes, 2017) menunjukkan bahwa Celebrity endorser memiliki pengaruh signifikan terhadap keputusan membeli. Selebriti digunakan oleh pemasar karena talenta, keberanian, keanggunan, ketampanan, kekuatan dan daya tarik fisiknya yang diharapkan oleh pemasar untuk mengiklankan produknya. Semakin tinggi atribut kredibilitas, daya tarik, keahlian, kepercayaan yang dimiliki celebrity endorser maka semakin besar pengaruhnya terhadap keputusan membeli.

Menurut(Shimp, 2013) terdapat lima bagian karakteristik endorser yaitu : 1) Kepercayaan 2) Keahlian; 3) Daya tarik fisik; 4) Rasa hormat dan 5) Kesamaan.

Berdasarkan tinjauan pustaka dan penelitian terdahulu, kerangka pemikiran disusun sebagai berikut :

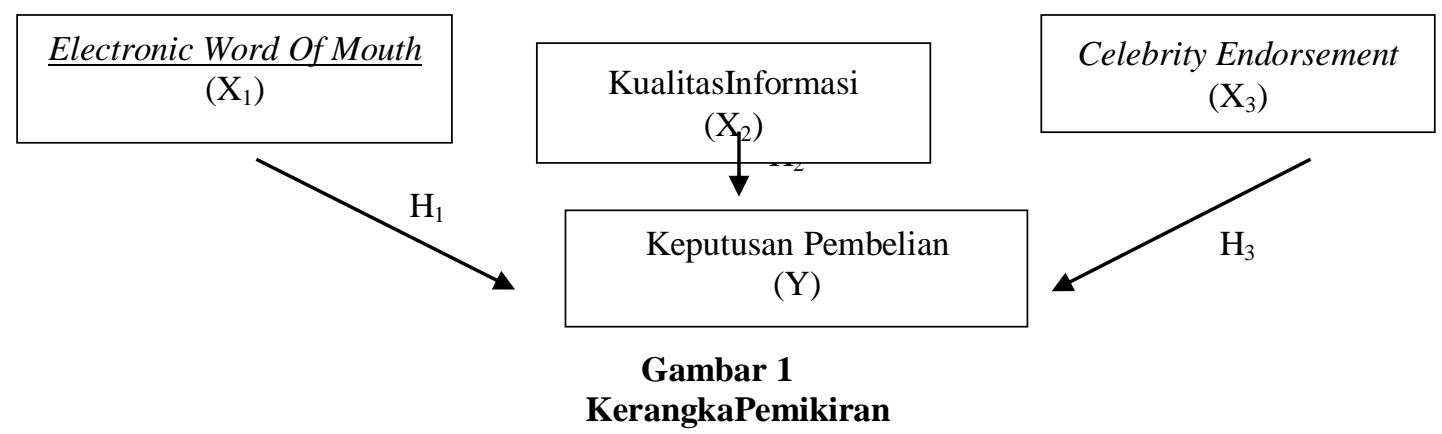

Hipotesis dalam penelitian adalah sebagai berikut :

$\mathrm{H}_{1}$ :Electronic word of mouth berpengaruh terhadap keputusan pembelian produk fashion muslim di Kota Madiun

$\mathrm{H}_{2}$ :Kualitas informasi berpengaruh terhadap keputusan pembelian produk fashion muslim di Kota Madiun

$\mathrm{H}_{3}$ :Celebrity endorsement berpengaruh terhadap keputusan pembelian produk fashion muslim di Kota Madiun

$\mathrm{H}_{4}$ :Electronic word of mouth, kualitas informasi dan celebrity endorsement berpengaruh secara simultan terhadap keputusan pembelian produk fashion muslim di Kota Madiun.

\section{METODE PENELITIAN}

Penelitian ini menggunakan metode deskriptif dan kuantitatif, bertujuan untuk 
mengetahui faktor-faktor yang memengaruhi keputusan pembelian produk fashion muslim di Kota Madiun di masa new normal pandemic Covid-19. Populasi penelitian adalah penduduk muslim di Kota Madiun. Sampel diambil dengan metode Slovin sebanyak 250 konsumen pembeli produk fashion muslim di 10 (sepuluh) took busana muslim di Kota Madiun. Teknik pengambilan sampel menggunakan metode non probability sampling yaitu teknik yang tidak member peluang sama bagi anggota populasi untuk dipilih menjadi sampel.Teknik pengumpulan data dilakukan melalui observasi, wawancara dan kuesioner(Ghozali, 2016).

Instrumen penelitian menggunakan kuesioner dan perlu dilakukan uji validitas dan reliabilitas untuk meninjau seberapa valid tidaknya butir pertanyaan yang diajukan kepada responden. Tingkat reliabilitas jawaban responden diukur dengan uji reliabilitas.

Analisis data menggunakan regresi linear berganda, namun sebelumnya perlu dilakukan pengujian asumsi klasik terlebih dahulu, agar data sampel yang diolah benar - benar dapat mewakili populasi secara keseluruhan. Asumsi klasik yang penting untuk diuji adalah: 1) Normalitas; 2) Multikolinieritas; 3) Heteroskedastisitas.

\section{HASIL DAN PEMBAHASAN}

\section{Analisis Data}

Hasil pengolahan data untuk uji validitas dan reliabilitas dapat dilihat pada tabel berikut:

Tabel 2

Hasil Uji Validitas Dan Reliabilitas Variabel Electronic Word of Mouth $\left(\mathrm{X}_{1}\right)$

\begin{tabular}{|c|c|c|c|c|c|c|}
\hline \multirow{2}{*}{$\begin{array}{l}\text { No. } \\
\text { Item }\end{array}$} & \multicolumn{3}{|c|}{ Validitas } & \multicolumn{3}{|c|}{ Reliabilitas } \\
\hline & r hitung & $r$ tabel & Keputusan & $\alpha$ Hitung & $\alpha$ Cronbach & Keputusan \\
\hline $\mathrm{X}_{1.1}$ & 0,369 & 0,197 & Valid & \multirow{11}{*}{0,766} & \multirow{11}{*}{0,60} & \multirow{11}{*}{ Reliabel } \\
\hline $\mathrm{X}_{1.2}$ & 0,374 & 0,197 & Valid & & & \\
\hline $\mathrm{X}_{1.3}$ & 0,348 & 0,197 & Valid & & & \\
\hline $\mathrm{X}_{1.4}$ & 0,358 & 0,197 & Valid & & & \\
\hline$X_{1.5}$ & 0,361 & 0,197 & Valid & & & \\
\hline$X_{1.6}$ & 0,345 & 0,197 & Valid & & & \\
\hline $\mathrm{X}_{1.7}$ & 0,591 & 0,197 & Valid & & & \\
\hline $\mathrm{X}_{1.8}$ & 0,502 & 0,197 & Valid & & & \\
\hline $\mathrm{X}_{1.9}$ & 0,510 & 0,197 & Valid & & & \\
\hline $\mathrm{X}_{1.10}$ & 0,383 & 0,197 & Valid & & & \\
\hline $\mathrm{X}_{1.11}$ & 0,401 & 0,197 & Valid & & & \\
\hline
\end{tabular}

Sumber : Hasil olah data, 2020 
BerdasarkanTabel 2 dapat disimpulkan bahwa semua item pernyataan tentang Electronic Word of Mouth (X1) dengan 250 responden mempunyai korelasi lebih besar dari r = 0,197 dan Cronbach alpha sebesar 0,766 > 0,60, berarti item pernyataan valid dan reliable sehingga dapat digunakan untuk pengujian selanjutnya.

Tabel 3

Hasil Uji Validitas Dan ReliabilitasVariabelKualitasInformasi $\left(\mathbf{X}_{2}\right)$

\begin{tabular}{|c|c|c|c|c|c|c|}
\hline \multirow{2}{*}{$\begin{array}{l}\text { No. } \\
\text { Item }\end{array}$} & \multicolumn{3}{|c|}{ Validitas } & \multicolumn{3}{|c|}{ Reliabilitas } \\
\hline & r hitung & $r$ tabel & Keputusan & $\alpha$ Hitung & $\alpha$ Cronbach & Keputusan \\
\hline $\mathrm{X}_{2.1}$ & 0,433 & 0,197 & Valid & \multirow{8}{*}{0,685} & \multirow{8}{*}{0,60} & \multirow{8}{*}{ Reliabel } \\
\hline $\mathrm{X}_{2.2}$ & 0,377 & 0,197 & Valid & & & \\
\hline $\mathrm{X}_{2.3}$ & 0,407 & 0,197 & Valid & & & \\
\hline $\mathrm{X}_{2.4}$ & 0,436 & 0,197 & Valid & & & \\
\hline $\mathrm{X} 2.5$ & 0,209 & 0,197 & Valid & & & \\
\hline $\mathrm{X} 2.6$ & 0,326 & 0,197 & Valid & & & \\
\hline $\mathrm{X} 2.7$ & 0,399 & 0,197 & Valid & & & \\
\hline $\mathrm{X} 2.8$ & 0,373 & 0,197 & Valid & & & \\
\hline
\end{tabular}

Sumber : Hasil pengolahan data, 2020

Berdasarkan Tabel 3 dapat disimpulkan bahwa semua item pernyataan tentang variabel KualitasInformasi $\left(\mathrm{X}_{2}\right)$ dengan 250 responden mempunyai korelasi lebih besar dari $\mathrm{r}=0,197$ dan Cronbach alpha sebesar 0,685 $>0,60$, berarti item pernyataan valid dan reliabel sehingga dapat digunakan untuk pengujian selanjutnya.

Tabel 4

Hasil Uji Validitas Dan Reliabilitas VariabelCelebrity Endorsement $\left(\mathrm{X}_{3}\right)$

\begin{tabular}{|c|c|c|c|c|c|c|}
\hline \multirow{2}{*}{$\begin{array}{l}\text { No. } \\
\text { Item }\end{array}$} & \multicolumn{3}{|c|}{ Validitas } & \multicolumn{3}{|c|}{ Reliabilitas } \\
\hline & $\mathbf{r}$ hitung & r tabel & Keputusan & $\alpha$ Hitung & $\alpha$ Cronbach & Keputusan \\
\hline $\mathrm{X}_{1.1}$ & 0,326 & 0,197 & Valid & \multirow{11}{*}{0,802} & \multirow{11}{*}{0,60} & \multirow{11}{*}{ Reliabel } \\
\hline $\mathrm{X}_{1.2}$ & 0,471 & 0,197 & Valid & & & \\
\hline $\mathrm{X}_{1.3}$ & 0,558 & 0,197 & Valid & & & \\
\hline $\mathrm{X}_{1.4}$ & 0,403 & 0,197 & Valid & & & \\
\hline $\mathrm{X} 1.5$ & 0,515 & 0,197 & Valid & & & \\
\hline $\mathrm{X} 1.6$ & 0,596 & 0,197 & Valid & & & \\
\hline $\mathrm{X} 1.7$ & 0,432 & 0,197 & Valid & & & \\
\hline $\mathrm{X} 1.8$ & 0,591 & 0,197 & Valid & & & \\
\hline X1.9 & 0,386 & 0,197 & Valid & & & \\
\hline $\mathrm{X} 1.10$ & 0,411 & 0,197 & Valid & & & \\
\hline $\mathrm{X} 1.11$ & 0,387 & 0,197 & Valid & & & \\
\hline
\end{tabular}

Sumber : Hasil pengolahan data, 2020

Berdasarkan Tabel 4 dapat disimpulkan bahwa semua item pernyataan tentang variabel Celebrity Endorsement $\left(\mathrm{X}_{3}\right)$ dengan 250 responden mempunyai korelasi lebih besar dari $\mathrm{r}=0,197$ dan Cronbach alpha sebesar 0,802 >0,60 berarti item pernyataan valid dan reliabel sehingga dapat digunakan untuk pengujian selanjutnya.

72| C A P I T A L, V O L UM E 4, NOMOR 1, S EPTEMBER 2020 
Tabel 5

Hasil Uji Validitas dan Reliabilitas Variabel Keputusan Pembelian (Y)

\begin{tabular}{|c|r|c|c|c|c|c|}
\hline \multirow{2}{*}{$\begin{array}{c}\text { No. } \\
\text { Item }\end{array}$} & \multicolumn{3}{|c|}{ Validitas } & \multicolumn{3}{c|}{ Reliabilitas } \\
\cline { 2 - 5 } & $\mathbf{r}$ hitung & $\boldsymbol{r}$ tabel & Keputusan & $\boldsymbol{\alpha}$ Hitung & $\boldsymbol{\alpha}$ Cronbach & Keputusan \\
\hline $\mathrm{Y}_{\cdot}$ & 0,220 & 0,197 & Valid & & & \\
\hline $\mathrm{Y}_{\cdot 2}$ & 0,467 & 0,197 & Valid & \multirow{2}{*}{0,696} & 0,60 & Reliabel \\
\hline $\mathrm{Y}_{\cdot 3}$ & 0,649 & 0,197 & Valid & & \\
\cline { 1 - 4 } $\mathrm{Y}_{\cdot 4}$ & 0,539 & 0,197 & Valid & & & \\
\hline $\mathrm{Y}_{\cdot 5}$ & 0,414 & 0,197 & Valid & & & \\
\hline
\end{tabular}

Sumber : Hasil pengolahan data, 2020

Berdasarkan 5dapatdisimpulkanbahwasemua item pernyataan tentangvariabel keputusanpembelian(Y) dengan 250 responden mempunyai korelasi lebih besar dari $\mathrm{r}=$ 0,197 dan Cronbach alpha sebesar 0,696> 0,60 berarti item pernyataan valid dan reliabel sehingga dapat digunakan untuk pengujian selanjutnya.

\section{Uji AsumsiKlasik}

Uji normalitas dilihat dengan normal probability plot. Grafik normal probability plot menggambarkan bahwa data mendekati distribusi normal. Hasil uji menggambarkan, data menyebar di sekitar garis diagonal dan mengikuti arah diagonal, sehingga dapat disimpulkan bahwa model regresi adalah normal.

Uji multikolinieritas dilakukan dengan melihat Value Inflation Factor (VIF) pada model regresi. Jika VIF lebih besar dari 5, variabel mempunyai persoalan multikolinearitas dengan variabel bebas lainnya(Ghozali, 2016).

Tabel 6. Uji Multikolinearitas

\begin{tabular}{|l|l|c|c|}
\hline \multicolumn{2}{|c|}{ Model } & \multicolumn{2}{c|}{ Collinearity Statistics } \\
\cline { 3 - 4 } \multicolumn{2}{|c|}{1} & Tolerance & VIF \\
\hline \multirow{3}{*}{} & (Constant) & & \\
\cline { 2 - 4 } & Electronic word of mouth & .548 & 1.824 \\
\cline { 2 - 4 } & KualitasInformasi & .501 & 1.997 \\
\cline { 2 - 4 } & Celebrity Endorsement & .695 & 1.439 \\
\hline
\end{tabular}

Sumber : Hasil pengolahan data, 2020

BerdasarkanTabel 6 diketahui bahwa nilai VIF untuk Electronic word of mouth sebesar 1.824, Kualitas informasi sebesar 1.997 dan Celebrity endorsementsebesar 1.439. Karena nilai VIF kurang dari 5, maka dapat disimpulkan bahwa pada model regresi tidak ditemukan adanya masalah multikolinearitas. 
Uji heterokedastisitas dilihat berdasarkan gambar scatterplot (Ghozali, 2016). Hasil diagram scatter plot yang diperoleh memperlihatkan titik-titik menyebar secara acak, tidak membentuk pola yang teratur, serta tersebar di segala arah, baik di atas maupun di bawah angka 0. Dengan demikian tidak terjadi masalah heterokedastisitas, hingga model regresi yang baik dan ideal dapat terpenuhi.

\section{Teknik Analisis Data}

Data hasil penelitian di analisis dengan menggunakan teknik Analisis Regresi Linier Berganda dan hasilnya disajikan pada tabel berikut :

Tabel 7. Hasil AnalisisRegresi

Coefficients $^{\mathrm{a}}$

\begin{tabular}{|l|l|c|c|c|c|c|}
\hline \multicolumn{2}{|c}{ Model } & \multicolumn{2}{|c|}{ Unstandardized Coeff. } & Standardized Coeff. & \multirow{2}{*}{ t } & \multirow{2}{*}{ Sig. } \\
\cline { 3 - 7 } & B & Std. Error & Beta & & \\
\hline \multirow{3}{*}{1} & (Constant) & 3.455 & 2.224 & & 1.554 & .124 \\
\cline { 2 - 7 } & electronic word of mouth & .088 & .059 & .166 & 2.203 & .036 \\
\cline { 2 - 7 } & kualitasinformasi & .182 & .095 & .222 & 2.021 & .048 \\
\cline { 2 - 7 } & celebrity endorsement & .157 & .047 & .328 & 3.355 & .001 \\
\hline
\end{tabular}

a. Dependent Variable: Keputusan Pembelian

Sumber : Hasil pengolahan data, 2020

BerdasarkanTabel7 model persamaan regresi linier berganda adalah:

$$
\begin{aligned}
& Y=a+b_{1} X_{1}+b_{2} X_{2}+b_{3} X_{3}+e \\
& Y=3,455+0,166 X_{1}+0,222 X_{2}+0,328 X_{3}+e
\end{aligned}
$$

Interpretasi persamaan regresi linier berganda tersebut dapat dijelaskan sebagai berikut:

a) Jika variable Electronic Word Of Mouth, Kualitas Informasi dan Celebrity Endorsement diabaikan, maka Keputusan Pembelian produk fashion muslim di Kota Madiun(Y) adalah sebesar 3,455

b) Jika Electronic Word of Mouth meningkat 1 satuan, maka Keputusan Pembelian produk fashion muslim di Kota Madiun akan meningkat sebesar 0,166 satuan dengan asumsi variabel $\mathrm{X}_{2}$ dan $\mathrm{X}_{3}$ tetap.

c) Jika Kualitas Informasi naik 1 satuan maka Keputusan Pembelian produk fashion muslim di Kota Madiun akan meningkat sebesar 0,222satuan dengan asumsi variabel $\mathrm{X}_{1}$ dan $\mathrm{X}_{3}$ tetap.

d) Jika Celebrity Endorsement meningkat 1 satuan, maka Keputusan Pembelian produk fashion muslim di Kota Madiun akan meningkat sebesar 0,328 satuan, dengan 74| C A P I T A L, V OLUME 4, NOMOR 1, SEPTEMBER 2020 
asumsi variabel $X_{1}$ dan $X_{2}$ tetap.

\section{Uji Hipotesis}

BerdasarkanTabel 7, dari hasil pengujian koefesien diketahui ada pengaruh signifikan variabelElectronic Word of Mouth terhadap Keputusan Pembelian. Hal ini dibuktikan dengan nilai koefisien beta sebesar 0,166 dan nilai probabilitas (Sign) sebesar 0,036 $(\mathrm{p}<0,05)$. Ada pengaruh signifikan variabel Kualitas Informasi terhadap Keputusan Pembelian. Hal ini dibuktikan dengan nilai koefisien beta sebesar 0,222 dan nilai probabilitas(Sign) sebesar $0,048(\mathrm{p}<0,05)$. Ada pengaruh signifikan variable Celebrity Endorsement terhadap Keputusan Pembelian. Hal ini dibuktikan dengan nilai koefisien beta sebesar 0,328 dan nilai probabilitas (Sign) sebesar 0,001 ( $\mathrm{p}<0,05)$.

Tabel 8. Hasil Uji F

ANOVA $^{\mathrm{a}}$

\begin{tabular}{|l|l|c|c|c|c|c|}
\hline \multicolumn{2}{|l|}{ Model } & Sum of Squares & Df & Mean Square & F & Sig. \\
\hline \multirow{4}{*}{1} & Regression & 325.948 & 3 & 108.649 & 18.040 & $.000^{\mathrm{b}}$ \\
\cline { 2 - 7 } & Residual & 578.162 & 246 & 6.023 & & \\
\cline { 2 - 7 } & Total & 904.110 & 249 & & & \\
\hline
\end{tabular}

a. Dependent Variable: keputusanpembelian

b. Predictors: (Constant),electronic word of mouth, kualitasinformasi,celebrity endorsement Sumber:Hasil pengolahan data, 2020

Berdasarkan Tabel 8,dapatdiketahuibahwa secara simultan/ serempak variabel Electronic Word of Mouth, KualitasInformasi dan Celebrity Endorsement berpengaruh signifikan terhadap Keputusan Pembelian produk fashion muslim di Kota Madiun. Hal itu dibuktikan dengan nilai $\mathrm{F}$ hitung lebih besar dari pada $\mathrm{F}$ tabel, pada tingkat keyakinan 95\% atau nilai probabilitas (Sign) sebesar 0,000 ( $<<0,05)$.

\section{Pembahasan}

\section{Pengaruh Electronic Word of Mouth terhadap Keputusan Pembelian Produk Fashion Muslim di Kota Madiun}

Berdasarkan hasil analisis diketahui ada pengaruh electronic word of mouth terhadap keputusan pembelian produk fashion muslim di Kota Madiun. Hal ini sesuai dengan hasil penelitian (Fitria \& Dwijananda, 2016) dan (Restanti et al., 2019)bahwa terdapat pengaruh electronic word of mouth terhadap proses keputusan pembelian. Hal ini diperkuat dengan penelitian mengatakan bahwa Electronic Word ofMouth dapat memengaruhi konsumen dalam membeli suatu produk. menyatakan proses pemasaran 
dengan menggunakan $e W o M$ dinilai lebih efektif bila diterapkan pada akun-akun media sosial yang dapat diakses oleh masyarakat luas. Terlebih lagi $e W o M$ dapat menyediakan sarana luas untuk dapat memengaruhi keputusan seseorang dalam membeli sebuah merk, jasa, ataupun produk tertentu.Hasil ini mendukung hipotesis yang diajukan, terbukti bahwa ada pengaruh electronic word of mouth terhadap keputusan pembelian produkfashion muslim di Kota Madiun.

\section{Pengaruh Kualitas Informasi terhadap Keputusan Pembelian Produk Fashion Muslim di Kota Madiun}

Berdasarkan hasil analisis diketahui bahwa ada pengaruh kualitas informasi terhadap keputusan pembelian produk fashion muslim di Kota Madiun. Hal ini sesuai dengan penelitian (Nazarudin \& Pela, 2016),(Hatta \& Salman, 2016) dan (Gunawan \& Ayuningtiyas, 2018) dimana temuan penelitian-penelitian tersebut menyebutkan bahwa variabel kualitas informasi berpengaruh terhadap variable keputusan pembelian.Hasil ini mendukung hipotesis yang diajukan bahwa terbukti ada pengaruh kualitas informasi terhadap keputusan pembelian produk fashion muslim di Kota Madiun.

\section{Pengaruh Celebrity Endorsement terhadap Keputusan Pembelian Produk Fashion Muslim di Kota Madiun}

Berdasarkan hasil analisis diketahui bahwa terdapat pengaruh celebrity endorsement terhadap keputusan pembelian produk fashion muslim di Kota Madiun. Hal ini didukung oleh penelitian oleh (Knoll \& Matthes, 2017), (Superwiratni, 2018) dan (Restanti et al., 2019) yang melakukan penelitian dengan temuan bahwa terdapat pengaruh signifikan antara celebrity endorsement terhadap keputusan pembelian. Hasil penelitian menunjukkan bahwa celebrity endorsement terdiri dari empat dimensi yaitu: visibility, credibility, attraction, dan power membawai mplikasi signifikan terhadap keputusan pembelian.

Indikator visibility, popularitas dan ketenaran endorser pada pemasaran produk fashion muslim di instagram dapat menarik dan memengaruhi konsumen untuk membeli produk tersebut. Indikator credibility, merupakan kecakapan dan objektifitas seorang endorser, pengetahuan endorser tentang produk yang dipasarkan dapat meyakinkan, membujuk dan menimbulkan rasa percayadiri pada konsumen produk fashion yang 76 | C A P I T A L, V O L UME 4, NOMOR 1, SEPTEMBER 2020 
dipasarkan di instagram. Indikator attraction, ketika seseorang melihat endorse produk fashion muslim di instagram dilakukan oleh selebriti atau tokoh publik yang menjadi favorit dan terkenal maka hal tesebut dapat memengaruhi dan membuat konsumen ingin membeli produk yang dipasarkan. Indikator power, seorang endorser produk fashion muslim mempunyai kemampuan dalam menarik konsumen untuk membeli produk yang ditawarkan. Hasil ini mendukung hipotesis yang diajukan bahwa terbukti ada pengaruh celebrity endorsement terhadap keputusan pembelian produk fashion muslim di Kota Madiun.

\section{Pengaruh Semua Faktor Secara Serempak}

Berdasarkan hasil analisis diketahui bahwa electronic word of mouth, kualitas informasi dan celebrity endorsement berpengaruh secara serempak terhadap keputusan pembelian produk fashion muslim di Kota Madiun. Faktor dominan yang memengaruhi keputusan pembelian produk fashion muslim di Kota Madiun adalah celebrity endorsement. Hasil ini mendukung hipotesis yang diajukan bahwa terbukti ada pengaruh secara serempak electronic word of mouth, kualitas informasi dan celebrity endorsement terhadap keputusan pembelian produk fashion muslim di Kota Madiun.

\section{E. SIMPULAN}

Berdasarkan analisis data dan pembahasan hasil penelitian, meski saat ini berada di era New Normal pandemic Covid-19, simpul temuan penelitian adalah sebagai berikut:

1. Ada pengaruh signifikan variable electronic word of mouth terhadap keputusan pembelian produk fashion muslim di Kota Madiun. Hal ini menunjukkan bahwa semakin besar nilai Electronic Word of Mouth yang dilakukan maka semakin besar pula keputusanpembeliankonsumen pada produkfashionmuslim. Informasi dan rekomendasi tentang produk fashion muslim dibagikan melalui akun Instagram dapat memengaruhi keputusan pembelian.

2. Ada pengaruh signifikan variable kualitas informasi terhadap keputusan pembelian produk fashion muslim di Kota Madiun. Hal ini menunjukkan bahwa semakin besar nilai kualitas informasi yang diberikan maka semakin besar pula keputusan pembelian konsumen pada produk fashion muslim.

77 | C A P I T A L, V O L UME 4, NOMOR 1, SEPTEMBER 2020 
3. Ada pengaruh secara parsial variable celebrity endorsement terhadap keputusan pembelian produk fashion muslim di Kota Madiun. Hal ini dapat diartikan bahwa semakin tinggi nilai Celebrity Endorser maka semakin tinggi pula keputusan pembelian pada konsumen.

4. Ada pengaruh secara serempak, variable electronic word of mouth, kualitas informasi dan celebrity endorsement terhadap keputusan pembelian produk fashion muslim di Kota Madiun.

\section{DAFTAR PUSTAKA}

Fitria, S. E., \& Dwijananda, I. M. (2016). Analisis Pengaruh Electronic Word of Mouth Terhadap Proses Keputusan Pembelian (studi pada Gojek). E-Proceeding of Management, 3(1), 1-20. https://openlibrary.telkomuniversity.ac.id/pustaka/files/107309/jurnal_eproc/analisi s-pengaruh-electronic-word-mouth-terhadap-proses-keputusan-pembelian-studipada-pt-gojek-di-kota-jakarta-bandung-surabaya-dan-bali.pdf

Ghozali, I. (2016). Aplikasi Analisis Multivariate Dengan Program IBM SPSS 23 (8th ed.). Universitas DIPONEGORO.

Gunawan, H., \& Ayuningtiyas, K. (2018). Pengaruh Kepercayaan, Kemudahan Dan Kualitas Informasi Terhadap Keputusan Pembelian Daring Di Aplikasi Bukalapak Pada Mahasiswa Politeknik Negeri Batam. Journal of Applied Business Administration, 2(1), 152-165. https://doi.org/10.30871/jaba.v2i1.763

Hatta, H., \& Salman, M. (2016). Keputusan Pembelian: Pengaruh Kualitas Informasi Dan Komunitas Virtual Samsung Galaxy Tab Di E-Commerce. Ekonomi Bisnis, 21(1), 105-121. https://doi.org/10.17977/um042v21i1p105-121

Knoll, J., \& Matthes, J. (2017). The effectiveness of celebrity endorsements: a metaanalysis. Journal of the Academy of Marketing Science, 45(1), 55-75. https://doi.org/10.1007/s11747-016-0503-8

Modjo, M. I. (2020). Memetakan Jalan Penguatan Ekonomi Pasca Pandemi. Jurnal Perencanaan Pembangunan: The Indonesian Journal of Development Planning, 4(2), 103-116. https://doi.org/10.36574/jpp.v4i2.117

Nazarudin, H., \& Pela, Y. (2016). PENGARUH KEMUDAHAN DAN KUALITAS INFORMASI TERHADAP KEPUTUSAN PEMBELIAN SECARA ONLINE DI SITUS D'BC NETWORK ORIFLINE (Studi Pada Masyarakat Fatufeto Kota Kupang). Jurnal Bisnis \& Manajemen, 2, 112-134. http://jurnal.pnk.ac.id/index.php/bisman/article/view/59

Rachmalika, B. (2015). Analisis Faktor-Faktor Pembentuk Electronic Word-of-Mouth 
Dan Pengaruhnya Terhadap Keputusan Pembelian Pada Restoran Hakata Ikkousha Jakarta. Jurnal Administrasi Bisnis S1 Universitas Brawijaya, 25(1), 86120. http://administrasibisnis.studentjournal.ub.ac.id/index.php/jab/article/view/978

Restanti, F., ... A. K.-J., \& 2019, U. (2019). Pengaruh Celebrity Endorser Dan Electronic Word of Mouth Terhadap Minat Beli Dan Dampaknya Terhadap Keputusan Pembelian. Jurnal Administrasi Bisnis (JAB), 68(1), 28-37. http://administrasibisnis.studentjournal.ub.ac.id/index.php/jab/article/view/2796

Rizki, K., Astuti, E. S., \& Susilo, H. (2015). Pengaruh Kemudahan Dan Kualitas Informasi Terhadap Minat Dan Keputusan Pembelian Secara Online. Jurnal Administrasi Bisnis, 28(1), 56-63. http://administrasibisnis.studentjournal.ub.ac.id/index.php/jab/article/view/1127/14 98

Shandy, B. (2018). The Effect of Celebrity Endorser and E-Wom On Purchase Decision of Yamaha Motor. Jurnal Digest Marketing, 3(1), 7-14. https://onlinejournal.unja.ac.id/digest/article/view/4395

Shimp, A. T. (2013). Periklanan dan Promosi. Salemba Empat.

Superwiratni, S. (2018). Pengaruh Celebrity Endorsement Terhadap Keputusan Menginap Di Cottage Daarul Jannah. THE Journal: Tourism and Hospitality Essentials Journal, 8(2), 99. https://doi.org/10.17509/thej.v8i2.13743

Wijaya, T., \& Paramita, L. (2014). PENGARUH ELECTRONIC WORD OF MOUTH ( eWOM ) TERHADAP KEPUTUSAN PEMBELIAN KAMERA DSLR. Econimics and Business, 9(Sancall), 12-19. 